\title{
Building libraries in the virtual age
}

\author{
By Charlene Hurt
}

\section{New considerations bring a new vision of academic libraries}

J ustifying the construction of new space in academic libraries has always been difficult, and the advent of the "virtual" or "digital" library has only added to that difficulty. About ten years ago the Council of Higher Education, Virginia, estimated that the state-supported academic libraries of the Commonwealth would need to construct nine acres of shelving if collection growth were to continue at the current rate. The response of the state's lawmakers was not to begin budget planning for new construction, but to begin looking for alternatives. The days when a simple formula of volume count and student population would generate funding for new space are clearly over.

What is needed is a vision of what the academic library of the 21 st century will be, and that recuires examining our basic assumptions about the future role the library will play in higher education. Involving faculty and students as well as librarians in developing that vision can be the beginning of a process that will result in funcling for a new kind of library integral to the teaching and learning process of the university.

\section{Envisioning the new age library}

Although the vision for the new library will vary from campus to campus, there are some assumptions I believe will be common to ali:

- teaching and learning are becoming more collaborative, and will continue to be;

- learning should be free of artificial space constraints;
- the new information environment will require constant training and updating;

- everyone will want to be connected;

- text and meclia will merge;

- electronic resources will change the role of paper.

If library design is informed by these assumptions, then the unspoken but most essential fact of libraries will continue to be true: the library as a "place" will continue to be an important part of university life.

- Teaching and learning are becoming more collaborative. A library designed for collaborative learning is not a quiet library where the primary interaction is between a scholar and a paper document. Library users need group study rooms and tables, individual and group carrels, and a mix of seating comfortable for various styles of working together. They also need access to media and technology in shared environments, which means everything has to be wired for power and network connections.

- Learning should be free of space constraints. Experiential learning takes place any-

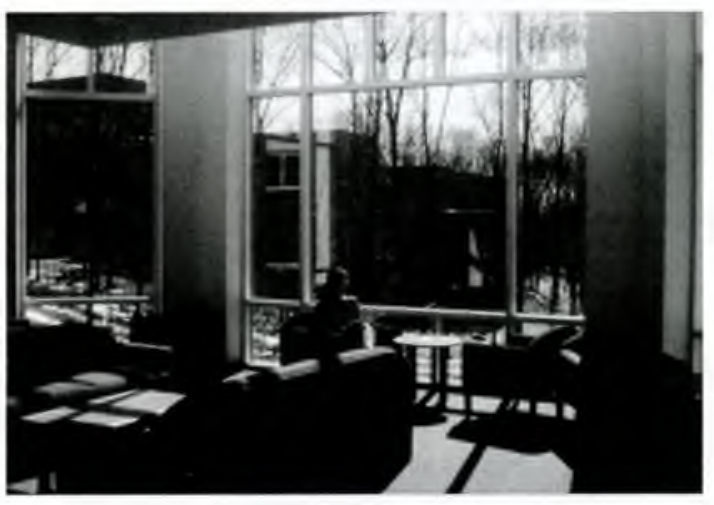

A study area in George Mason University's new George W. Johnson Center. 
where, anytime, in a variety of environments, often social. A library that sets itself aside as a "temple of learning" where quiet and austerity prevail will please the needs of a particular subset of the student population, but will alienate many others. The popularity of bookstores that serve drinks and food demonstrates a preference for a more casual, social environment, as does our students' preference for seating in highly visible areas, and their use of headphones to listen to music while they study.

- Constant training and retraining will be necessary in the new information environment. The information environment is in a constant state of change, and information professionals are needed more than ever to monitor the changes, design systems to exploit new resources, and teach faculty and students how to use those systems. Early fears of librarians that we might become redundant in the world of automated systems have been replaced by fears that we can't possibly meet the demand for training and coaching. We've also come to realize that we have to accommodate a variety of learning styles, including classroom instruc-

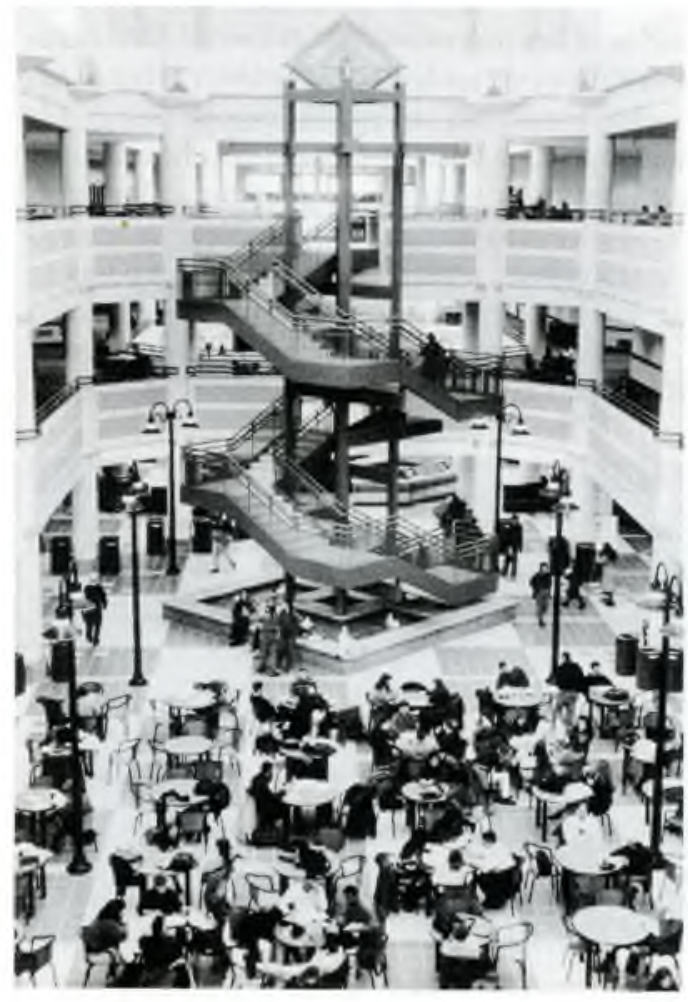

GMU's new George W. Johnson Center combines a 100,000-square-foot library with meeting, programming, and food service space. tion, small group coaching, individual appointments, and drop-in assistance. So new library design has to include a flexible, networked library instruction room, workstation carrels that can seat small groups, a reference and/or information desk to respond to drop-ins, and nearby offices for more sustained consultation.

- Everyone needs to be connected. Students increasingly carry their own computers with them, and are looking for places to plug them in and get access to the campus network. Most, if not all, seats in the library should be wired for power and access, using carrels and tables with adequate wire management systems to permit flexibility in furniture placement. Libraries will also need to think about developing check-out systems for equipment that students may need to get connected, and for laptops for students who don't have their own.

- The merger of text and media. Libraries that can't provide graphical interfaces and image-based systems are in danger of seeming irrelevant to students and faculty, but providing the technology necessary for that access is expensive and raises a whole new set of issues regarding security, printing costs, and appropriate use of library computing. Libraries need to plan for extensive multimedia use, including student requests to incorporate media into their research assignments and presentations.

- Electronic resources change the role of paper. Not every library has to be an archival library, especially in multilibrary systems. Increasingly, archives will be electronic, especially for journals, and it will be easier to provide access to materials not owned. Freed from archival restraints, libraries can rethink their need for ever-increasing stacks, restricted areas, automatic binding of paperbacks, and environments free from food or drink. The gains in flexibility when one chooses to install fivefoot stacks instead of seven-foot stacks may be worth the loss of shelves.

Each library will have to work with a different set of circumstances and constraints in planning for additional space, but the necessity for examining the basic assumptions upon which our decisions are based is essential and must include informed guesses about how libraries will evolve. The one assumption we haven't always addressed is the most important:

- Libraries are and will continue to be important as places in academic communities. There are many reasons why students (New age cont. on page 91) 


\section{Break new ground}

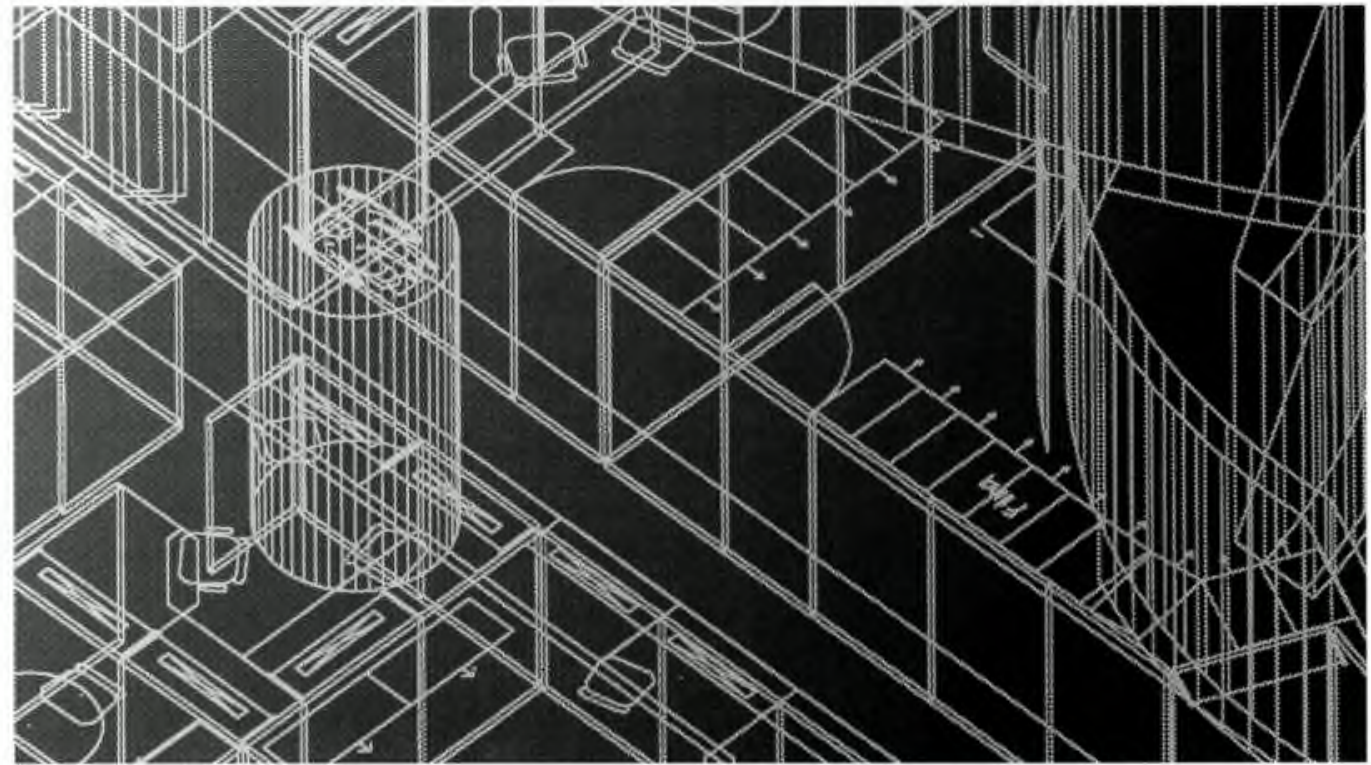

The foundation for innovation? Complete knowledge of research activity. So consider ISI ${ }^{\oplus}$ Citation Indexes your blueprint for new ideas. Reach back to uncover concepts from before your time... and develop groundwork for what lies ahead. Our indexes help you plot the course of your research, absorb predecessors' thinking, study your contemporaries' work...then make your mark on the future. With each cited reference you consult, you gather more precise information that will shape your work into exactly what you need. Such comprehensive search results are unattainable with any other service.

ISI Citation Indexes. Plan for groundbreaking discoveries.

\section{Building better research}

\section{Citation Indexes}

exclusively from

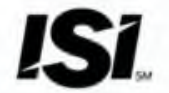

Institute for Scientific Information ${ }^{\mathrm{sm}}$

For more information, call 1-800-336-4474 or 215-386-0100

ISI Europe: +44-1895-270016 ISI Japan: +81-3-5562-3571

http://www.isinet.com 


\section{The State of the Art}

Information industry leaders in providing subscription services, article delivery \& library automation software.

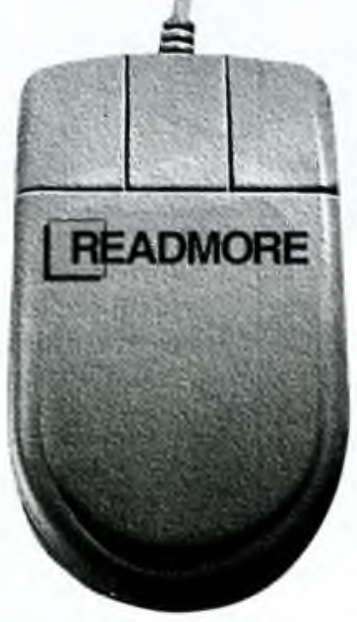

...working

smart

ROSS $^{\star}$ Online ordering, claiming and searching of journal and publisher databases.

Remo ${ }^{\bar{R}}$ Mouse driven serials management system.

Electronic Interfaces \& Customized Automated Management Products

ReadiCat Our comprehensive Internet catalog of serial titles searchable by a number of access points.

\section{Backserv/BackMed}

Internet lists solely devoted to the informal exchange of serial back issues among libraries.

World Wide Web http://www.readmore.com

READMORE, INC.

22 Cortlandt Street

New York, NY 10007

Fax: 212-233-0746

READMORE IS A BLACKWELL COMPANY 
mega-sites. Access: http://www.shss.montclair. edu/english/furr/media.html

- CRAYON. Create Your Own Newspaper. Selection is a breeze in a well-executed, stepby-step design. The site allows you to select the type of news links and from where. It also lists which sites, in order of preference, are picked by those who've created their own paper before you; more than 60,000 people have. Access: http://crayon.net/

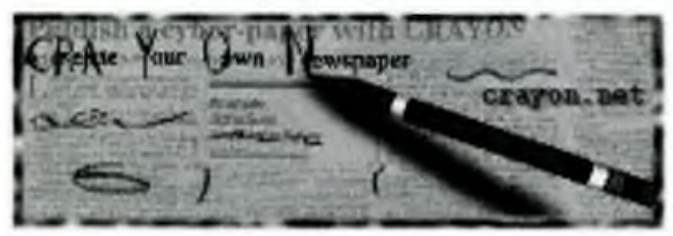

- FCC-The Federal Communications

Commission. Regulates interstate, international communications by radio, television, wire, satellite, and cable. Lists links to all of the FCC's business. Also listed is the Telecommunications Act of 1996. Access: http://www.fcc.gov/

- Communications Decency Act of 1996. A site all librarians should know about since there are now challenges in the courts from ALA and other groups. Information is broken down into broad sections within subsections. Access: http://www rahul.net/starowl/ cda-text.htm.

- Journalist's Toolbox. Produced by the National Scholastic Press Association and Associated Collegiate Press. This site is aimed at university, college, and high school newspapers and press people. Very useful sites for all aspects of mass media and publishing-related sites. Nicely laid out and alphabetical in orientation. Easy to look at and use. Access: http:// studentpress.journ.umn.edu/Toolbox.html.

- Media Watchdog. Offers links to sites that watch media sources and emphasizes watching and discussing the accuracy and bias in the mainstream media. The site is broken down into five subject groups: time sensitive information, media criticism organizations and resources, media criticism articles, censorship resources, and other resources. Access: http:// theory.lcs.mit.edu/ mernst/media/.

- The EraM program. Here is a site with an interest in issues relating to ethnicity, racism, and the media aimed at academics, students, and media professionals. Listed are some megasites, TV/radio sites, organizations, and academic sites. Access: http://www.brad.ac.uk/ research/eram/wwwsites.html.
(New age cont, from page 76)

and faculty go to libraries, and only one of them is to gain access to collections. If a library system wants to reassert its right to be considered the heart of the university, it needs to think about those reasons, and make sure its building plans take them into account. Here are some of the reasons I think there will always be a need for library buildings:

- students and faculty need the assistance of information professionals and will prefer to secure that assistance in person whenever possible;

- students need places where information resources are available so they can meet with classmates to work together on class projects;

- students need to get out of noisy dorm rooms and family homes so they can concentrate on their studies;

- libraries frequently will have better workstations, printers, and/or network connections than are available to students or faculty at home;

- students and faculty like the ambiance of libraries (and bookstores) and find it conducive to learning;

- students are social beings, and like being in the midst of other people.

An example of how these assumptions have informed the building of a new library can be seen at George Mason University's Johnson Center, which includes a library, bookstore, food services, theater, Media Authoring Center, and student and academic program offices. For a preview, go to our homepage at http:// ulcweb.gmu.edu. Ed. note: See C\&RL News, May 1996, for an overview of the center.

\section{Learn more about building libraries}

If you enjoyed this article, you may want to attend the preconference Hurt developed for ACRL called "Building the New Age Library," Friday, April 11, 1:00-4:30 p.m., in Nashville. It will cover new ways of thinking about library buildings and provide practical examples using the Johnson Center at GMU, including its food services, book store, computer labs, movie theater, and more. For registration information see the preliminary program in the January issue of CERL News or check the conference homepage at http: //www.ala.org/acrl.html. 